\title{
AVALIAÇÃO DA CONTAMINAÇÃO AMBIENTAL POR CARBOFURANO EM SOLO PROVENIENTE DO CULTIVO DE CANA-DE-AÇÚCAR
}

\author{
Adilson Correia Goulart ${ }^{1}$, Simone Machado Goulart ${ }^{2}$, Maraína Souza Medeiros ${ }^{3}$ João Paulo Victorino Santos ${ }^{2}$

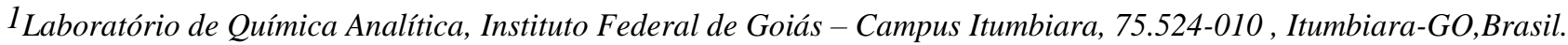 \\ ${ }^{2}$ Departamento de Áreas Acadêmicas, Instituto Federal de Goiás - Campus Itumbiara, 75.524-010, Itumbiara-GO,Brasil. \\ 3 Programa de Pós-Graduação em Meio Ambiente e Qualidade Ambiental, Universidade Federal de Uberlândia, 38.400-902, \\ Uberlândia-MG, Brasil.
}

*E-mail: adilson.goulart@ifg.edu.br

\begin{abstract}
RESUMO
Segundo o Sindicato Nacional da Indústria de Produtos para Defesa Vegetal, de 2012 a 2014, cerca de $10 \%$ do total de agrotóxicos comercializados no Brasil foram destinados para o setor sucroalcooleiro. Dentre os agrotóxicos recomendados pela ANVISA no controle de pragas em canaviais destaca-se o princípio ativo carbofurano. De acordo com relatório do IBAMA, nos anos de 2010 e 2013 foram comercializados, respectivamente, cerca de 2000 e 1700 toneladas de carbofurano em diferentes regiões do Brasil, incluindo os Estados de Goiás e Minas Gerais. Dessa forma, esta pesquisa objetivou a verificação da existência de contaminação do solo por carbofurano em amostras provenientes do plantio de cana-de-açúcar. A área selecionada para verificar a ocorrência de contaminação localiza-se na divisa dos Estados de Goiás e Minas Gerais onde o cultivo de cana-de-açúcar é cada vez mais predominante. As amostras foram retiradas em profundidade de $0-20 \mathrm{~cm}$. As coletas foram realizadas em duas estações diferentes do ano de 2016, sendo a primeira realizada no final do mês de maio e a segunda em meados do mês de novembro. O método analítico utilizado para verificar a existência de contaminação do solo pelo agrotóxico carbofurano foi a extração sólido-líquido com partição a baixa temperatura, seguida de análise por cromatografia líquida de alta eficiência, acoplada a um detector ultravioleta. Nas condições de análise estabelecidas e dentro do limite de detecção do método aplicado, não foram encontrados resíduos de carbofurano nas amostras provenientes da área avaliada.
\end{abstract}

Palavras-chave: Contaminação do solo. Agrotóxico carbofurano. ESL-PBT solo.

\section{Introdução}

A cana-de-açúcar é uma das principais culturas plantadas no Brasil. Segundo a União da Indústria de Cana-de-Açúcar (UNICA), em 2015 foram plantados quase 11 milhões de hectares em todo país, sendo que em Goiás esta parcela foi de pouco mais de 967 mil, já no Estado de Minas Gerais o cultivo ultrapassou a marca de 1 milhão de hectares plantados [1]. O setor canavieiro movimenta cerca de $2 \%$ do Produto Interno Bruto (PIB) e é considerado uma das principais fontes de cogeração de energia elétrica nacional. Somando a utilização do bagaço e a produção de etanol, ambas representam aproximadamente $16 \%$ da cogeração de energia do país [2]. Além de ser uma importante fonte energética outros produtos advindos do caldo da cana e da sua biomassa estão presentes de forma direta ou indireta na economia como, por exemplo, o açúcar utilizado praticamente em todos os ramos industriais e na alimentação humana, produção de ração animal, fabricação de cachaça, remédios, dentre outros [3].

A produção de cana-de-açúcar é importante para diversas áreas, fazendo-se presente em importantes seguimentos da indústria e na comodidade humana. $\mathrm{O}$ aumento na demanda de biocombustíveis e o fortalecimento do setor sucroenergético têm pressionado o setor a produzir maiores quantidades em um período de tempo cada vez menor. Essa produtividade intensa e dinâmica só se faz possível devido à implementação agrícola como, por exemplo, a utilização de agrotóxicos e fertilizantes sintéticos. No entanto, essas substâncias podem ocasionar sérios impactos ao meio ambiente, dentre os quais podemos citar a degradação do solo e poluição dos sistemas terrestres [4-5].

As principais doenças e pragas observadas nos canaviais são ocasionadas pela infestação de nematoides e/ou insetos. A invasão desses seres vivos nas plantações pode gerar inúmeras adversidades na qualidade do produto final e até mesmo interferir na produtividade, podendo comprometer toda uma safra [6]. Dentre as inúmeras classes de nematoides, os mais prejudiciais para a qualidade da cana são as Meloidogyne javanica, Meloidogyne incognita e Pratylenchus zeae. Em relação aos insetos, os que proporcionam maiores preocupações são: Mahanarva fimbriolata conhecida popularmente como cigarrinha-das-raízes; Besouro Sphenophorus levis, também 
chamado de gorgulho da cana-de-açúcar; Migdolus ou besouro da cana-de-açúcar e Cupins das espécies Heterotermes tenuis, Procornitermes, Nasutitermes, Neocapritermes, Syntermes e Cornitermes cumulans [7].

Segundo a Agência Nacional de Vigilância Sanitária (ANVISA) alguns dos princípios ativos autorizados para o controle de pragas em lavoura de cana-de-açúcar são: Fipronil, Bifentrina, Imidacloprid, Endosulfan, e Carbofurano [8]. Segundo o Sindicato Nacional da Indústria de Produtos para Defesa Vegetal (SINDIVEG), de 2012 a 2014, cerca de $10 \%$ do total de agrotóxicos comercializados no Brasil foram destinados ao setor sucroalcooleiro. De acordo com o Portal de Dados Abertos Sobre Agrotóxicos, nesse período foram aproximadamente 220 mil toneladas de diferentes princípios ativos aplicados em canaviais de todo o país.

O carbofurano pertence à família química dos carbamatos, sendo considerado muito perigoso ao meio ambiente e classificado como substância extremamente tóxica aos seres vivos [9]. É aplicado diretamente no solo e também em sementes. O princípio ativo é autorizado para as culturas de algodão, arroz, amendoim, banana, batata, café, cana-de-açúcar, cenoura, feijão, fumo, milho, repolho, trigo e tomate [8]. Dois produtos formulados a partir do princípio ativo carbofurano são indicados para o controle de insetos e nematoides em culturas de cana-deaçúcar, sendo eles o Furadan ${ }^{\circledR} 50$ GR e Furadan ${ }^{\circledR} 100$ GR. O primeiro destina-se ao controle da cigarrinha-das-raízes e diferentes classes de nematoides. Sua aplicação ocorre incorporada ao solo ou juntamente com os toletes de cana muda, no ato do plantio [10]. Já a formulação 100 GR é indicada para o extermínio de cupins das classes Heterotermes tenuis, do besouro Mygdolus e alguns tipos de nematoides como, por exemplo, os Meloidogyne incógnita, Meloidogyne javanica e Pratylenchus zeae. A aplicação desta formulação acontece somente incorporada ao solo [11].

O relatório de comercialização de agrotóxico, organizado pelo Instituto Brasileiro de Meio Ambiente (IBAMA), em 16 anos de publicação divulgou informações a respeito da comercialização do carbofurano apenas nos anos de 2010 e 2013. Foram, respectivamente, cerca de 2.000 e 1.700 toneladas do princípio ativo comercializadas em quase todas as regiões do país, com destaque para os Estados de São Paulo e Minas Gerais, que ficaram nessa ordem, em primeiro e segundo lugar na utilização dessa substância. Em Goiás, a soma dos dois anos equivaleram a pouco mais de 71 toneladas de carbofurano utilizadas [12]. Uma pesquisa realizada por Rodrigues e colaboradores [13] na cidade de Itumbiara, localizada na região sul do Estado de Goiás, constatou que 100\% dos produtores entrevistados utilizavam algum princípio ativo em suas plantações, sendo o carbofurano um dos agrotóxicos citados.

Ao serem aplicados na agricultura para o controle de pragas, além de atingirem os seres-alvo, grande parte dos agrotóxicos movimenta-se pelos componentes terrestres. O solo é o ambiente que recebe a maior parcela dos resíduos excedentes, o deslocamento das moléculas acontece principalmente pela evaporação, lixiviação e escoamento superficial [14-16].

De acordo com Gomes e colaboradores [17], quando se tem a pretensão de investigar a contaminação de solo por agrotóxicos é de suma importância o conhecimento prévio das características físico-químicas do princípio ativo. Tal medida se faz necessária para determinação da profundidade em que a amostra será coletada. Os autores destacam ainda duas propriedades indispensáveis nesta análise que são o $\mathrm{K}_{\mathrm{oc}} \mathrm{e} \mathrm{o}$ índice de GUS. Amostras de solo tratadas com princípios ativos com valores de $\mathrm{K}_{\mathrm{oc}}$ altos $\left(600 \leq \mathrm{K}_{\mathrm{oc}} \leq 4.999\right)$ ou muito altos $\left(\mathrm{K}_{\mathrm{oc}}>\right.$ 5000) devem ser coletadas superficialmente. Já as amostras cujo tratamento foi realizado com agrotóxicos com baixos valores de $\mathrm{K}_{\mathrm{oc}}\left(0,5 \leq \mathrm{K}_{\mathrm{oc}} \leq 99\right)$ recomenda-se coletá-las desde a superfície até certa profundidade. Esta profundidade deve levar em consideração o grau de lixiviação do princípio ativo fazendo uso do índice de GUS. Para os agrotóxicos na faixa $1,8 \leq \mathrm{GUS} \leq 2,8$ orienta-se uma amostragem de 0-10 cm e 10-20. Para agrotóxicos com baixo potencial de lixiviação GUS < 1,8 a coleta deve acontecer na superfície devendo ser observado os prováveis caminhos do escoamento superficial [17].

As áreas de cultivo, em sua maioria, estão localizadas próximas a grandes bacias hidrográficas tendo, como consequência, a degradação ambiental, o que potencializa a necessidade de pesquisas que visem à verificação de índices de contaminação nestas áreas [18]. A área selecionada neste estudo para verificar a ocorrência de contaminação por carbofurano em solo localiza-se na divisa dos Estados de Goiás e Minas Gerais, onde o cultivo de cana-de-açúcar é cada vez mais predominante. $\mathrm{O}$ canavial situa-se às margens do rio Paranaíba em terreno levemente inclinado e inexistem barreiras físicas entre a área de cultivo e o rio (latitude $18^{\circ} 25^{\prime} 49.7^{\prime \prime} \mathrm{S}$; longitude $49^{\circ} 11^{\prime} 36.68^{\prime \prime} \mathrm{O}$ ), com precipitação anual média de $1.489 \mathrm{~mm}$ [19]. Tais características favorecem o processo de escoamento superficial da água, provenientes da chuva e/ou provindas de irrigação, podendo ocasionar o desaguamento de substâncias tóxicas, como, por exemplo, o carbofurano, advindas dos tratos culturais dessa cultura. Além da alta periculosidade ambiental, o carbofurano é um agrotóxico extremamente perigoso à fauna aquática. Desse modo, análises preventivas que visem à verificação de concentrações do princípio ativo no solo antes de períodos com altos índices pluviométricos e processo de irrigação, são de grande valia para a prevenção da contaminação das águas superficiais, como, por exemplo, as do rio Paranaíba, que é um significativo curso d'água para os Estado de Goiás e Minas Gerais, além de desaguar em importantes bacias hidrográficas como as do rio Grande e rio Paraná [19-20].

Tendo em vista o exposto, esta pesquisa teve como objetivo verificar a existência de contaminação ambiental no solo proveniente do cultivo de cana-de-açúcar em terreno localizado entre os Estados de Goiás e Minas Gerais. Para verificar a 
ocorrência de resíduos de carbofurano nas amostras de solo foi utilizado o método de extração sólido-líquido com partição a baixa temperatura seguida de análise em cromatógrafo líquido de alta eficiência.

\section{Metodologia}

\subsection{Coleta e preparo das amostras de latossolo vermelho}

A área avaliada foi dividida em 5 subáreas, para a divisão foram medidas 5 distâncias, ao longo do canavial, de \pm 100 metros. Para a coleta foi respeitado o sistema de coordenadas geográficas utilizando-se um aplicativo de localização instalado em aparelho celular. Na Figura 1 é apresentado o esquema de coleta das amostras, assim como as respectivas localizações geográficas de cada amostra simples coletada.

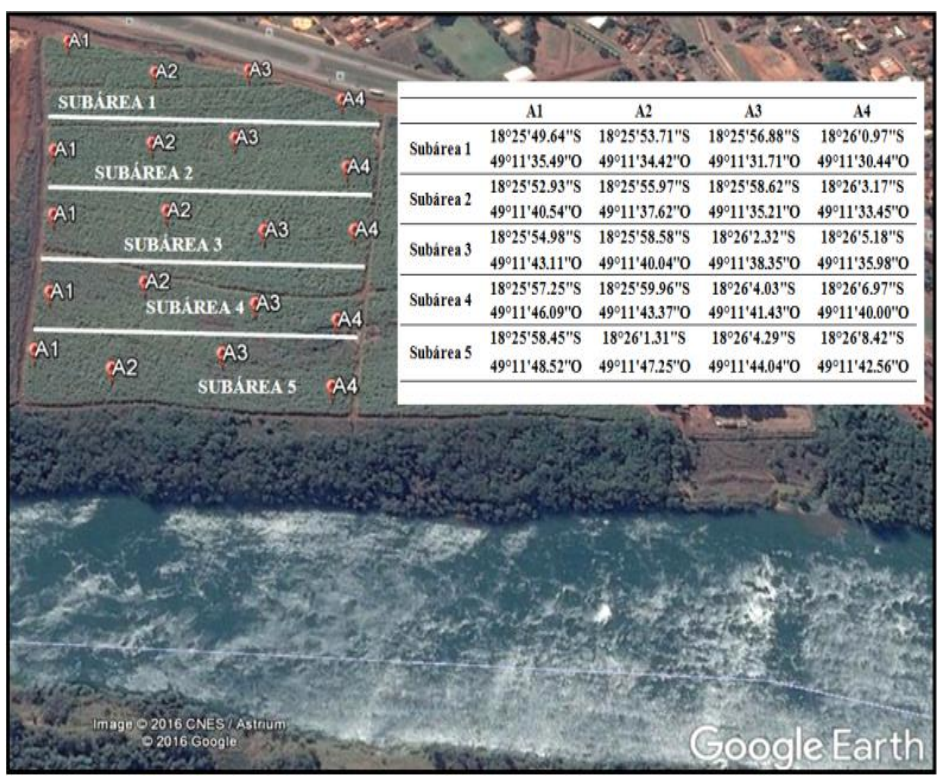

Figura 1 - Esquema de coleta das amostras de latossolo vermelho e suas respectivas localizações geográficas [21] Adaptado.

Em cada uma das 5 subdivisões foram retiradas 4 amostras simples. Conforme recomendado por Gomes e colaboradores [17], cada amostra foi coletada respeitando as propriedades físico-químicas do carbofurano $\left(\mathrm{K}_{\mathrm{oc}}=22 \mathrm{~mL} \mathrm{~g}^{-1} \mathrm{e}\right.$ índice de GUS igual a 4,725), sendo, portanto, coletadas a uma profundidade de $0-20 \mathrm{~cm}$. As 4 amostras simples, referentes a cada subárea, foram coletadas em um mesmo recipiente resultando em 5 amostras compostas representando cada subárea. Cada amostra foi seca a temperatura ambiente e peneirada em malha de aço inox $2 \mathrm{~mm}$ separadamente. Em seguida, foram identificadas e guardadas em caixa acrílica com tampa em freezer até o momento da análise. As coletas foram realizadas em duas estações diferentes. A primeira foi realizada no final de maio de 2016 e a segunda em meados do mês de novembro de 2016.

\subsection{Extração e análise das amostras de latossolo vermelho}

Cada amostra foi analisada em triplicata. Para a extração nas matrizes de latossolo vermelho foi utilizado o método de extração sólido-líquido com partição a baixa temperatura conforme descrito por Goulart [22]. Para o procedimento foi pesado 1,0000 grama de cada amostra, secas a temperatura ambiente, em frascos de vidro com tampa e com capacidade volumétrica de $22 \mathrm{~mL}$. Ao sistema foram adicionados $1,5 \mathrm{~mL}$ de água deionizada, $4 \mathrm{~mL}$ acetonitrila seguida de homogeneização de 30 segundos em agitador de tubos vortex. Posterior à agitação, o sistema repousou em freezer por duas horas a uma temperatura de aproximadamente $-20{ }^{\circ} \mathrm{C}$. Após o tempo de partição retirou-se uma alíquota do sobrenadante para injeção em cromatógrafo a líquido de alta eficiência acoplado a detector ultravioleta.

\subsection{Condições cromatográficas}

O cromatógrafo foi configurado com as seguintes condições cromatográficas: Detector de UV a $195 \mathrm{~nm}$; Coluna Kinetex $5 \mu \mathrm{m}$ EVO C 18 - 150 X 4,6 mm; fase móvel (modo isocrático); Acetonitrila:Água deionizada 35:65 v/v; Vazão da fase móvel: $0,8 \mathrm{~mL} \min ^{-1}$; Temperatura da coluna: $35{ }^{\circ} \mathrm{C}$; Volume de injeção: $20 \mu \mathrm{L}$; e Tempo de análise: 7 minutos.

\subsection{Identificação e quantificação do carbofurano nas amostras}

$\mathrm{Na}$ análise cromatográfica, a identificação do analito na matriz ocorreu por meio da verificação do tempo de retenção do mesmo após o processo de extração e injeção no equipamento. Desta maneira, o tempo de retenção do carbofurano foi determinado pela injeção de uma solução em acetonitrila contendo o padrão carbofurano na concentração de $5 \mathrm{mg} \mathrm{L}^{-1}$.

Para a quantificação de possíveis concentrações de resíduos de carbofurano nas amostras foi construída uma curva analítica com o padrão de carbofurano em acetonitrila nas concentrações de 0,$1 ; 0,3 ; 0,5 ; 1,0 ; 3,0 ; 5,0 ; 8,0 ; 10,0 \mathrm{mg} \mathrm{L}^{-1}$. Além disso, com a estimativa do coeficiente de determinação $\left(\mathrm{R}^{2}\right)$ da curva foi possível averiguar a linearidade de resposta do detector do equipamento.

\subsection{Fortificação das amostras com padrão carbofurano}

Com o intuito de verificar a eficiência do método de extração aplicado, foi realizado procedimento de fortificação das amostras com padrão carbofurano nas concentrações de 0,2 e 5 $\mathrm{mg} \mathrm{L}^{-1}$. Para a fortificação das amostras foi pesado 1,0000 grama de amostra na qual foram adicionadas diferentes quantidades de solução do padrão carbofurano a fim de se obter nos extratos finais concentrações de 0,2 e $5 \mathrm{mg} \mathrm{L}^{-1}$. Após fortificação, as amostras foram deixadas em repouso por um período de 3 horas para total evaporação da acetonitrila. Posteriormente, o sistema foi submetido ao processo de extração citado no item 2.2.

\section{Resultados e discussões}




\subsection{Análise do tempo de retenção do carbofurano}

Para a verificação do tempo de retenção do princípio ativo foi injetada uma solução do padrão carbofurano em acetonitrila na concentração de $5 \mathrm{mg} \mathrm{L}^{-1}$. Nas condições cromatográficas utilizadas foi verificado um tempo de retenção igual a 5,3 minutos para o agrotóxico em questão, conforme mostrado na Figura 2.

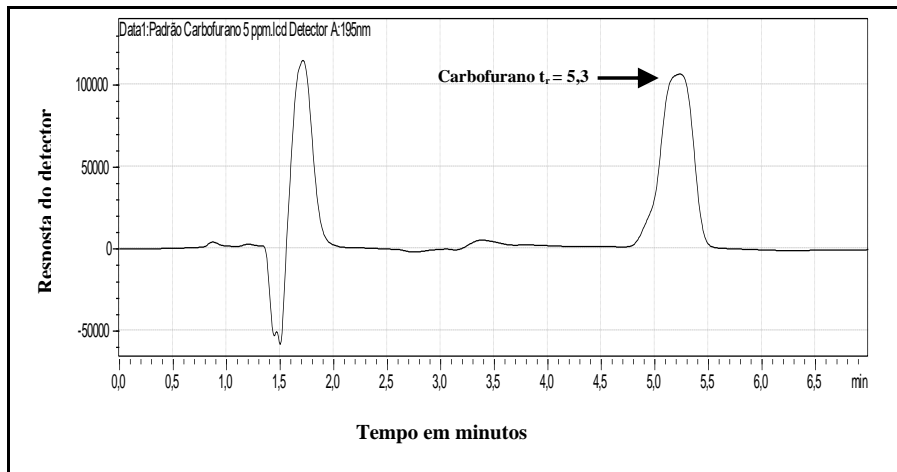

Figura 2 - Cromatograma obtido por meio da injeção de uma solução padrão de carbofurano a $5 \mathrm{mg} \mathrm{L}^{-1}$

\subsection{Curva analítica}

Para a quantificação do carbofurano nas matrizes de latossolo vermelho foi construída uma curva analítica do padrão em acetonitrila em diferentes concentrações. Na Figura 3 é apresentada a curva analítica assim como seus coeficientes de correlação (r) e determinação $\left(\mathrm{R}^{2}\right)$. Como visto, os valores de $\mathrm{r}$ e $\mathrm{R}^{2}$ foram superiores a 0,99 conferindo o ajuste e a linearidade das respostas do detector conforme orientado pela ANVISA em sua Resolução 899/2003 [23].

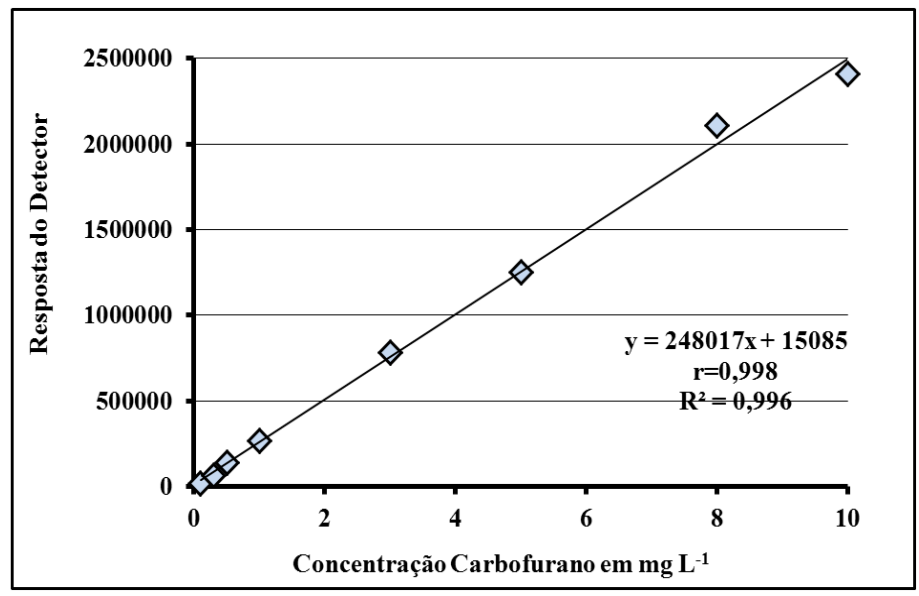

Figura 3 - Curva analítica do padrão carbofurano em acetonitrila.

\subsection{Análise de carbofurano nas amostras de latossolo vermelho}

Todas as 5 subáreas foram analisadas em triplicata em ambos os períodos de coleta adotados. As amostras depois de peneiradas e secas ao ambiente foram submetidas ao processo de extração sólido-líquido com partição a baixa temperatura. A adoção de duas estações distintas para a investigação do agrotóxico carbofurano em áreas de cultivo de cana foi uma estratégia adotada para avaliar se a sazonalidade interfere na detecção desse analito, uma vez que Chiarello e colaboradores [24] relataram que fatores como características pedológicas e do próprio agrotóxico, condições climáticas e topográficas da região em estudo influenciam na mobilidade e identificação dessas substâncias. Além disso, conforme Matias e Tamanaha [25], quando o agrotóxico fica adsorvido no solo este pode sofrer inúmeras reações químicas, físicas e biológicas. Na Figura 4 são apresentados dois cromatogramas resultantes das análises cromatográficas onde: (A) equivale às amostras coletadas no mês de maio de 2016 e (B) corresponde às amostras coletadas em meados do mês de novembro do mesmo ano.
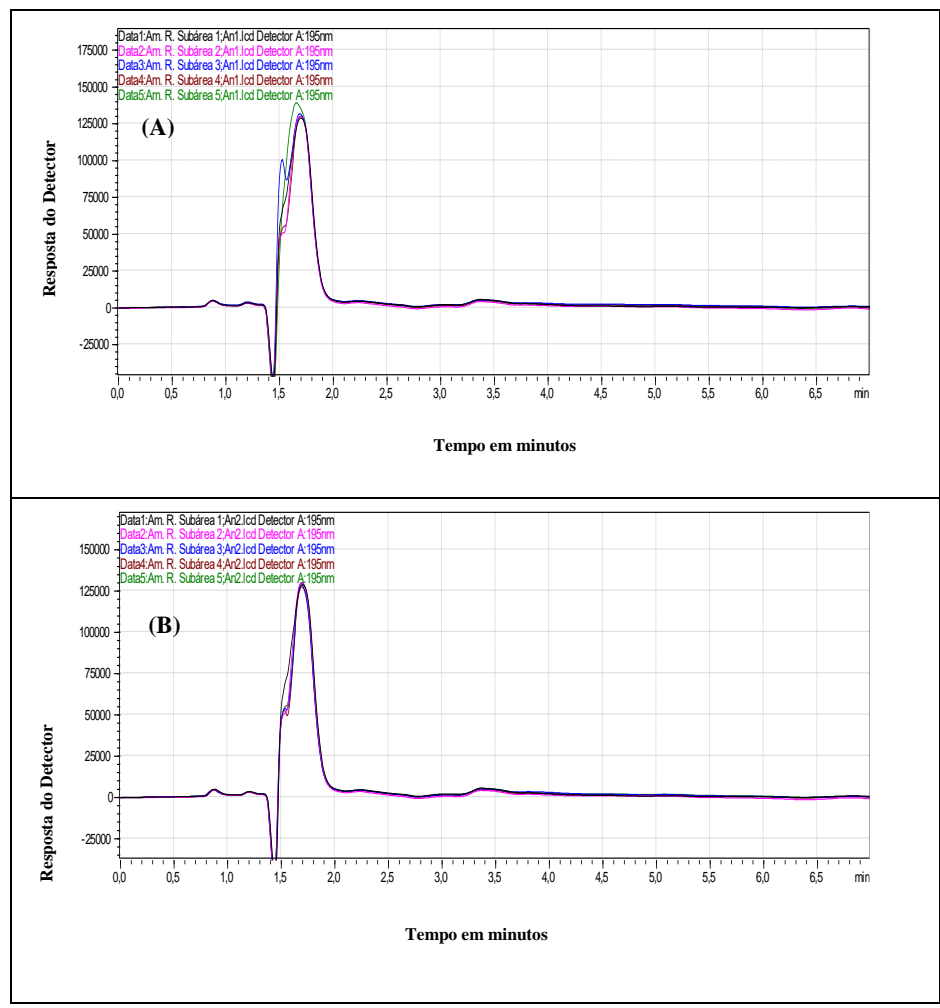

Figura 4 - Cromatogramas obtidos pela ESL-PBT em amostras de latossolo vermelho provenientes do cultivo de cana-de-açúcar, onde a figura (A) corresponde às análises ocorridas no mês de maio/2016 e (B) representa as avaliações feitas em novembro/2016.

Como pode ser verificado na Figura 4, tanto no mês de maio quanto no mês de novembro, em nenhum dos pontos analisados foi observado pico no tempo de retenção do agrotóxico carbofurano $\left(\mathrm{t}_{\mathrm{r}}=5,3\right)$. Dessa maneira, é possível constatar que, nas condições de análise estabelecidas e dentro do limite de detecção do método empregado $\left(0,025 \mathrm{mg} \mathrm{L}^{-1}\right)$, não foi 
constatada a presença de carbofurano nas amostras analisadas de latossolo provenientes do cultivo de cana-de-açúcar.

Resultado semelhante foi encontrado por SantiagoMoreira e colaboradores [26]. Em seus estudos, os autores analisaram a contaminação do solo por carbofurano em amostras oriundas do cultivo de arroz irrigado no Estado de São Paulo. Neste estudo as amostras foram coletadas por quase um ano e em todas elas não foram detectadas concentrações de carbofurano. Em contrapartida, Otieno e colaboradores [27], ao investigarem contaminação ambiental em solo no Quênia, país situado na África ocidental, detectaram extensiva contaminação do solo por resíduos de carbofurano. Os autores relataram que o princípio ativo foi extensivamente utilizado e que a contaminação se estendeu para águas superficiais e até mesmo para pequenos pássaros e mamíferos.

Em se tratando de resultados positivos para contaminação ambiental por resíduos de carbofurano, amostras de água superficial têm demonstrado maior incidência de contaminação. Em sua pesquisa, Back e colaboradores [28] analisaram amostras de águas superficiais localizadas próximas ao cultivo de arroz irrigado no sul de Santa Catarina, sendo encontrados resíduos de carbofurano durante os três anos de coleta. Já Silva e colaboradores [29] avaliaram a contaminação ambiental em águas superficiais, em regiões orizícolas no sul do Brasil, sendo encontrados resíduos de carbofurano nas amostras de água em todas as áreas analisadas. Em uma pesquisa mais abrangente, Mattos e colaboradores [30] realizaram um estudo com a intenção de monitorar agrotóxicos em águas subterrâneas, de superfície e em sedimento. Os resultados analíticos obtidos pelos autores apontaram que o carbofurano foi um dos princípios ativos com maior frequência de detecção nas amostras analisadas.

Uma possível explicação para a menor incidência na detecção do carbofurano no solo e maiores determinações em águas pode estar nas suas propriedades físico-químicas, isso porque, segundo a International Union of Pure and Applied Chemistry (IUPAC), no solo o tempo de meia vida deste composto é cerca de 29 dias, o que o classifica como substância não persistente. Já em ambientes aquáticos em algumas condições, como, por exemplo, variações de $\mathrm{pH}$, o princípio ativo pode ter o tempo de meia-vida prolongado, estendendo o seu tempo de meia-vida e, consequentemente, prolongando a sua permanência neste componente [31-32].

Embora o tempo de permanência do agrotóxico carbofurano no solo seja considerado curto [31], vale ressaltar que a principal via de contaminação dos recursos hídricos por agrotóxicos é o solo [14]. Desta maneira, análises preventivas a fim de se verificar a concentração, seja de carbofurano ou de qualquer outra substância nociva ao meio ambiente, são de grande importância. Ademais, o acompanhamento analítico de amostras provenientes de solos agrícolas seria de grande valia para se evitar a aplicação extensiva de agrotóxicos e, assim, diminuir as chances de contaminação dos recursos hídricos em períodos de maior precipitação ou durante práticas de irrigação.

\subsection{Avaliação da eficiência da ESL-PBT nas amostras reais fortificadas}

Após verificação de ausência do analito carbofurano nas amostras analisadas, foi realizado um estudo para constatar a seletividade da ESL-PTB nas amostras em estudo. Para isso, as amostras foram fortificadas com o padrão carbofurano na concentração de $0,2 \mathrm{mg} \mathrm{L^{-1 }}$. Na Figura 5 é apresentado o cromatograma resultante da ESL-PBT nas amostras fortificadas.

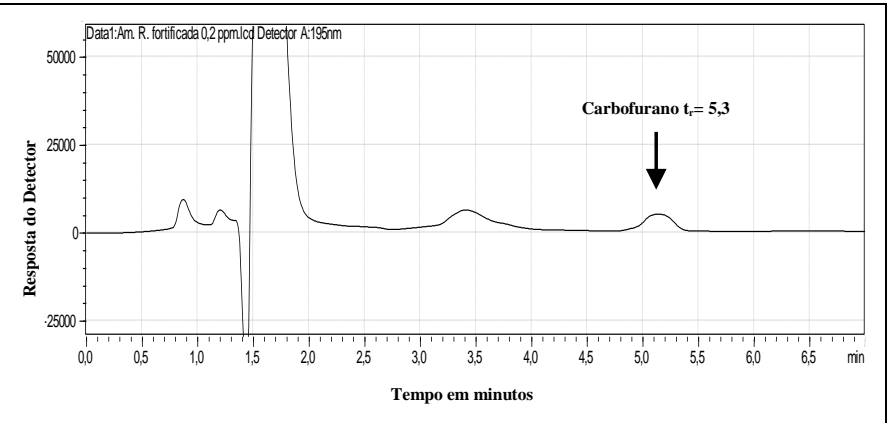

Figura 5 - Cromatograma obtido pela ESL-PBT em amostra fortificada a $0,2 \mathrm{mg}$ $\mathrm{L}^{-1}$.

No cromatograma apresentado na Figura 5 observa-se a presença de um pico no tempo de retenção do carbofurano $t_{r}=5,3$ minutos. Desta forma fica confirmada a seletividade do método de análise empregado e comprovada a não contaminação da área analisada.

\section{Conclusões}

Por meio dos resultados cromatográficos obtidos nesta pesquisa foi possível concluir que nas condições de análises estabelecidas, e dentro do limite de detecção do método analítico utilizado, a área avaliada não apresentou contaminação por resíduos de carbofurano em ambas as épocas analisadas. Além disso, com a fortificação das amostras foi possível verificar a seletividade do método para o carbofurano nas amostras analisadas. Alguns fatores podem ser apontados para a não detecção do carbofurano nesta área avaliada: O principal é que possivelmente este canavial não tenha sido tratado com $o$ princípio ativo em questão; A outra possibilidade seria a rápida degradação deste composto no solo.

\section{Agradecimentos}

Ao Instituto Federal de Goiás, campus Itumbiara, pelas condições físicas e materiais que possibilitaram a realização desta pesquisa. 


\section{EVALUATION OF THE ENVIRONMENTAL CONTAMINATION BY CARBOFURAN OF SOIL USED IN SUGARCANE CULTIVATION}

ABSTRACT: According to the National Association of the Plant Defense Products Industry (Sindiveg), from 2012 to 2014 about $10 \%$ of all pesticides sold in Brazil were destined for the sugarethanol sector of the economy. Among the pesticides recommended by ANVISA (National Health Surveillance Agency) for pest control in plantations is the active ingredient carbofuran. A report by IBAMA (Brazilian Institute of Environment and Renewable Natural Resources) states that, in 2010 and 2013, respectively, around 2000 and 1700 tons of carbofuran were commercialized in different regions of Brazil, including the states of Goiás and Minas Gerais. Thus, this study aimed to verify the existence of soil contamination by carbofuran in samples from sugar cane plantations. The selected area for this investigation is located in the border of the states of Goiás and Minas Gerais, in the Southeast region of the country, where the cultivation of sugarcane is becoming more prevalent. The samples were taken in $0-20 \mathrm{~cm}$ depth. The analytical method used to verify the existence of soil contamination by carbofuran was solid-liquid extraction with low temperature partition, followed by analysis by high-performance liquid chromatography, coupled to an ultraviolet detector. The samples were collected in two different seasons of the year 2016, the first at the end of May and the second in mid-November. Within the established analysis conditions and the detection limit of the applied method, evidence of contamination by carbofuran was not found in the samples from the evaluated area.

Keywords: Soil contamination. Carbofuran pesticide. SLE-LTP in soil

\section{Referências}

[1] UNIÃO DA INDÚSTRIA DE CANA-DE-AÇÚCAR. Unicadata, área cultivada com cana-de-açúcar. 2016.2 Disponível em: $\langle$ http://www.unicadata.com.br/historico-de-area-ibge.php $>$. Acesso em: 29 out. 2016.

[2] AGÊNCIA NACIONAL DE ÁGUAS (Brasil). Plano de recursos hídricos e do enquadramento dos corpos hídricos superficiais da bacia hidrográfica do rio Paranaíba. Brasília, DF, 2015. 73 p.

[3] NEVES, M. F.; TROMBIN, V. G.; CONSOLI, M. O mapa sucroenergético do Brasil. In: SOUSA, E. L. L. de; MACEDO, I. de C. (Coord.). Etanol e bioeletricidade: a cana-de-açúcar no futuro da matriz energética. São Paulo: Luc Projetos de Comunicação, 2010. p. 14-43.

[4] CAMELINI, J. H. Regiões competitivas do etanol e vulnerabilidade territorial no Brasil: o caso emblemático de Quirinópolis, GO. 2011. 129 f. Dissertação (Mestrado em Geografia) - Instituto de Geociências, Universidade Estadual de Campinas, Campinas, 2011
[5] DUARTE, C. G. Planejamento e sustentabilidade: uma proposta de procedimentos com base na avaliação de sustentabilidade e sua aplicação para o caso do etanol de cana-de-açúcar no Plano Decenal de Expansão de Energia. 2013. Tese (Doutorado em Ciências - Programa de Pós-Graduação em Ciências da Engenharia Ambiental) - Escola de Engenharia de São Carlos, Universidade de São Paulo, São Carlos, 2013.

[6] DINARDO-MIRANDA, L. L.; GIL, M. A.; COELHO, A. L.; GARCIA,V.; MENEGATTI, C. C. Efeito da torta de filtro e de nematicidas sobre as infestações de nematóides e a produtividade da cana-de-açúcar. Nematologia Brasileira, Vol. 27, p. 61-67, 2003.

[7] DINARDO-MIRANDA, L. L. Nematóides e pragas de solo em cana-deaçúcar. Informações agronômicas, Vol. 110, n. 1, p. 25-32, 2005. Disponível em: $<$ http://www.ipni.net/publication/iabrasil.nsf/0/B1FA44831820884083257AA1006BC 838/\$FILE/Enc25-32-110.pdf >. Acesso em: 1 nov. 2016.

[8] AGÊNCIA NACIONAL DE VIGILÂNCIA SANITÁRIA (Brasil). Regularização de produtos agrotóxicos: monografias autorizadas. 2017. Disponível em: <http://portal.anvisa.gov.br/registros-eautorizacoes/agrotoxicos/produt os/monografia-de-agrotoxicos/autorizadas $>$. Acesso em: 3 jul. 2017.

[9] UNIVERSITY OF HERTFORDSHIRE. PPDB: pesticide properties data base. Hertfordshire, 2017. Disponível em: http://sitem.herts.ac.uk/aeru/ppdb/en/Reports/118.htm>. Acesso em: 03 jul. 2017.

[10] BRASIL. Ministério da Agricultura, Pecuária e Abastecimento. Furadan ${ }^{\circledR}$ 50GR. Inseticida e Nematicida sistêmico, do grupo químico Metilcarbamato de Benzofuranila. Sob $\mathrm{n}^{\mathrm{o}}$ 00468590. 2016. Disponível em: < http://www.adapar.pr.gov.br/arquivos/File/defis/

DFI/Bulas/Inseticidas/FURADAN_50_GR.pdf >. Acesso em: 05 nov. 2016.

[11] _. Furadan ${ }^{\circledR}$ 100GR. Inseticida e Nematicida sistêmico, do grupo químico Metilcarbamato de Benzofuranila. Sob nº 02088591. 2016. Disponível em: < $\quad$ http://www.adapar.pr.gov.br/arquivos/ File/defis/DFI/Bulas/Inseticidas/FURADAN _100_G. pdf >. Acesso em: 05 nov. 2016 .

[12] IBAMA. Relatório de Comercialização de Agrotóxicos. 2016. Disponível em: < < http://www.iba ma.gov.br/index.php?option=com_content $\&$ view=article $\&$ id=594\&Itemid=546>. Acesso em: 05 Nov. 2016.

[13] RODRIGUES, V. C. et al. Aspectos Ambientais, Forenses e de Saúde Pública em relação ao uso de Agrotóxicos em um Município do Estado de Goiás, Brasil. Sinergia, Vol. 17, n. 1, p. 56-62, 2016.

[14] WEBER, J. B. Properties and behavior of pesticides in soil. In: HONEYCUTT, R. C.; SCHABACKER, D. J. Mechanisms of pesticide movement into ground water. Lewis Publishers. chap.2, p. 15-41, 1994.

[15] STEFFEN, G. P. K.; STEFFEN, R. B.; ANTONIOLLI, Z. I. Contaminação do solo e da água pelo uso de agrotóxicos. Tecno-Lógica, Vol. 15, n. 1, p. 15-21, 2011 .

[16] SILVA, C. M. M. S.; FAY, E. F. Agrotóxicos e ambiente. Brasília: Embrapa Informação. Tecnológica, 2004. 400 p. ISBN 85-7383-282-7.

[17] GOMES, M. A. F. et al. Amostragem de solos para análise de agrotóxicos. In: FILIZOLA, H. F. GOMES, M. A. F.; SOUZA, M. D. Manual de procedimentos de coleta de amostras em áreas agrícolas para análise da qualidade ambiental: solo, água e sedimentos. Jaguariúna: Embrapa Meio Ambiente, 2006. 
[18] ARAÚJO, L. E.; SANTOS, M. J.; DUARTE, S. M.; OLIVEIRA, E. M. Impactos ambientais em bacias hidrográficas - Caso da Bacia do Rio Paraíba. Tecno-lógica, Vol. 13, n. 2, p. 109-115, 2010.

[19] AGÊNCIA NACIONAL DE ÁGUAS (Brasil). Plano de recursos hídricos e do enquadramento dos corpos hídricos superficiais da bacia hidrográfica do rio Paranaíba. Brasília, DF, 2015. 73 p.

[20] COMITÊ DA BACIA HIDROGRÁFICA DO RIO PARANAÍBA. 2013. Disponível em: 〈http://cbhparanaiba.org.br/index.php〉. Acesso em: 08 nov. 2016.

[21] [MAPA da região de estudo]. In: GOOGLE maps. 2017. Disponível em: < https://www.google.com.br/maps/@-18.4354314,

49.1960373,4278a,20y,90h/data=!3m1!1e3>. Acesso em: 02 Nov. 2016.

[22] GOULART, A. C. Otimização e aplicação da extração sólido líquido com partição a baixa temperatura para determinação de carbofurano em solo. 2017.99 f. Dissertação (Mestrado em Meio Ambiente e Qualidade Ambiental) Universidade Federal de Uberlândia, Uberlândia, Brasil. 2017.

[23] AGÊNCIA NACIONAL DE VIGILÂNCIA SANITÁRIA (Brasil); RE $n^{\circ}$ 899, de 29/05/2003: Guia para validação de métodos analíticos e bioanalíticos, Ministério da Saúde: Brasil, 2003.

[24] CHIARELLO, M. et al. Determinação de agrotóxicos na água e sedimentos por HPLC-HRMS e sua relação com o uso e ocupação do solo. Quim. Nova, Vol. 40, n. 02, p. 158-165, 2017.

[25] MATIAS, V. A.; TAMANAHA, M. da S. Monitoramento dos agrotóxicos quinclorac e carbofuran no Rio Camboriú, município de Camboriú, Santa Catarina. Revista de Estudos Ambientais - REA, Vol. 18, n. 01, p. 30-45, 2016.

[26] SANTIAGO-MOREIRA, M. R. et al. Estudo do inseticida carbofurano em solo e sedimento de área de produção de arroz irrigado e controle do gorgulho aquático Oryzophagus oryzae, Taubaté, São Paulo, Brasil. Arquivos do Instituto Biológico, 2013

[27] OTIENO, P.O. et al. Soil and water contamination with carbofuran residues in agricultural farmlands in Kenya following the application of the technical formulation Furadan. J Environ Sci Health B. 2010 Feb;45(2):137-44. doi: $10.1080 / 10934520903425459$.

[28] BACK, A. J. et al. Ocorrência de agrotóxicos em águas usadas com irrigação de arroz no sul de santa Catarina. RBCIAMB, n.39. 2016, 47-58. DOI: 10.5327/Z2176-9478201611014.

[29] SILVA, D. R. O. et al. Monitoramento de agrotóxicos em águas superficiais de regiões orizícolas no sul do Brasil. Ciência Rural, Santa Maria, v.39, n.9, p.2383-2389, dez, 2009.

[30] MATTOS, M. L. T. et al. Monitoramento de agrotóxicos em áreas piloto da produção integrada de arroz irrigado na planície costeira externa e fronteira oeste do Rio Grande do Sul. Pelotas: Embrapa Clima Temperado, 2011. 4 p. (Embrapa Clima Temperado. Documentos, 197).

[31] IUPAC. International Union of Pure and Applied Chemistry. Footprint pesticides properties database. [Consult. 14 set. 2017] Disponível na internet: < http://sitem.herts.ac.uk/aeru/iupac/Reports/118.htm >

[32] TOMLIN, C. D. S. (Ed.). The pesticide manual. 11th ed. Farnham, Surrey, UK: British Crop 0Protection Council, 2000. USEPA - United States Environmental Protection Agency. Pesticides Fact Sheet. 24p. 